\title{
EVOLUTION OF SYSTEMATIC CHARACTERS IN THE FERNS ${ }^{1}$
}

\author{
INTRODUCTION \\ Thomas N. TAYloR ${ }^{2}$ ANd John T. MickeL ${ }^{3}$
}

For many years studies on living and fossil ferns have progressed with relatively little communication between researchers. This situation has been partially alleviated recently by the organization of the Pteridology Section of the Botanical Society of America. This symposium is one of the first fruits of such cooperation and coordination, and we hope that additional forms of interaction at all levels will be developed.

It has been more than ten years since sections of the Botanical Society of America have engaged in a symposium with ferns as the principal theme. In the introduction to the published volume resulting from that symposiumOrigin and Evolution of Ferns-it was noted, "A symposium such as this could not have been possible ten years ago. It is obvious that most of the significant advances reported in each of the papers have taken place very recently. It is encouraging, for that reason, to believe that within the next ten years we can expect similar strides, and that we will be much closer to understanding just what a fern is, where it came from, and how it got that way." The ten years since those comments were made have passed, and during that time a number of significant advances have been made that have greatly altered ideas about ferns, and possibly more importantly, have directly influenced future research paths in pteridology. But of potentially far greater significance is the fact that we have seen both neo- and paleopteridologists cross traditional and functional boundaries in the application of new research techniques in pteridological research. Some of the approaches in one field will be of only passing interest to those of the other because of inherent limitations, but it is vital that both areas better understand the progress and limitations of the other field. This symposium provides an appropriate opportunity to review the current level of information and future research directions in pteridological research.

In modern ferns we have a valuable research tool in chromosome counts. Such studies are of particular value in examining hybridization and in supporting genetic and familial relationships. We have found great aneuploid series in certain groups such as Gleicheniaceae and Dennstaedtiaceae; groups that today have only scattered fragments of the series. Additional counts will assist in refining certain taxonomic problems. Promising studies are being made on karyotyping and other detailed studies of the chromosomes. The study of population biology is not generally thought of as a systematic character, but it

1 "Evolution of Systematic Characters in the Ferns," papers presented at a jointly sponsored symposium of the Paleobotanical and Pteridological Sections of the Botanical Society of America and the American Fern Society held at Amherst, Massachusetts, in June 1973, under the chairmanship of Thomas N. Taylor.

${ }^{2}$ Department of Botany, The Ohio State University, Columbus, Ohio 43210.

s The New York Botanical Garden, Bronx, New York 10458.

Ann. Missouri Bot. Gard. 61: 307-309. 1974. 
appears likely that it will prove helpful in interpreting variation patterns and increase our overall appreciation of the genetic potential within ferns.

Fern systematics has relied heavily on reproductive features in the past Distinctions between the eusporangium and leptosporangium have broken down, and distinctive types such as that with an apical annulus, appear to have arisen independently in separate groups of ferns. Although one may no longer depend entirely on this feature, future research on the sporangium in coming years should provide information about sporangial variation and its systematic value.

Fern spores display remarkable variation and have been extremely helpful in systematic studies. In many cases particular spore morphologies are distinctive for families or genera, or in some instances individual species. Spore sizes and abortion have been useful in studies of hybridization and polyploidy, and in some cases they have led to the discovery of unknown reproductive variations in ferns. A broad detailed survey of spores is still needed to better understand variation patterns and to see which ones are meaningful taxonomically. Wall ultrastructure and development, including the organization and significance of the perispore, are areas of investigation that deserve critical examination. The extrapolation of these results would be of great value for paleobotanical studies where developmental approaches are not feasible.

Great strides have been made in recent years on the diversity and evolution within the heterosporous ferns. Links between homosporous and heterosporous ferns are still conjectural, but as research in this area continues many relationships will be clarified in the next several years.

Systematic chemical studies in the ferns are still in their infancy. Flavanoid chemistry appears quite promising and has been useful in studying hybridization and closely related species. Additional work on anteridogens and their activity will be helpful, and together with a detailed analysis of all chemicals in ferns, might be helpful in broad phylogenetic considerations.

The general organography of ferns is not as clear cut as previously thought. Current work with both living and fossil ferns is helpful in interpreting the variation in these organs. Detailed morphological and developmental studies are shedding light on the nature and significance of branching patterns and the evolution of the leaf. Anatomical studies are stressing stele organization and variation, apices and development, and various aspects of leaf structure and architecture. One of the few families in which good living and fossil material has been critically examined anatomically is the Marattiaceae. The detailed work on Psaronius has been very enlightening in showing diversity in the fossil members of this group.

In attempting to identify the precursors of ferns or in linking modern taxa with fossil ferns, there are many obstacles to overcome. Apparently, there are no true ferns in the Devonian, or more pointedly, their morphology and anatomy differ in enough features to make recognition by modern fern characters difficult at this time.

In attempting to construct a phylogeny of the ferns, there are two basic problems that deter us from placing all groups with confidence. First, there is the lack of a complete fossil record. There is little that can be done in this 
area except to continue looking, especially for the early ferns of perhaps Mississippian age, and the transitions to modern ferns in the early Mesozoic. The second concerns the lack of complete information on all ferns, especially the modern taxa. Broad studies are needed for almost all features of ferns. Studies on petioles, venation patterns, stomata, organ development, spores, mucilage ducts, and chemistry of the mucilage are all promising areas for future research. In recent years several aspects of the gametophyte phase have been elucidated, but still only a relatively small percentage of ferns are known in which the gametophyte has been critically examined. Different reproductive mechanisms have been found, and more work will undoubtedly show we have not yet exhausted the possibilities. Various aspects of fern chemistry, physiology, and genetics are areas that need concentrated effort.

The papers included in this symposium reflect our own biases and interests, and present only a fragmentary survey of the variety of potential approaches that might be included in a volume such as this. With the diversity of approaches available for studies of both modern and fossil ferns, it appears quite probable that our understanding of ferns will be further enhanced in the next few years. Another symposium on this same topic five years from now will have even greater advances to report. 